\title{
DEVELOPMENT OF THE PERSONNEL POTENTIAL OF A SANATORIUM-RESORT COMPLEX IN THE DIGITAL TRANSFORMATION OF ECONOMY ${ }^{1}$
}

\author{
Natalia A. Simchenko \\ V.I. Vernadsky Crimean Federal University, Simferopol, Russian Federation \\ Anna A. Yanovskaya \\ V.I. Vernadsky Crimean Federal University, Simferopol, Russian Federation
}

\begin{abstract}
The existing organizational and economic relations of health resort institutions of the Republic of Crimea and the impact of their personnel potential on improving the quality of medical services predetermine the need to develop a proposal to increase the export of medical services in the health resort complex of the Republic of Crimea through the transformation of staff competencies in the conditions of digitalization. The study of foreign and domestic scientific papers reveals the impact of the digitalization process on the transformation of employment, as well as the relationship between the three components of the effective work process: automation, employment and labor productivity. In the process of analyzing official statistical indicators of the health resort sector, it has been determined that the revenue from the services provided by health resort organizations has a growing trend. At the same time, the values of indicators of the average number of employees of health resorts and the number of accommodated foreign citizens have the greatest negative deviation. Based on the results of the study, a model of key competencies of personnel providing medical, therapeutic, health and rehabilitation services in the sanatoriumresort complex has been developed. The model is aimed at increasing the quality of health resort services and attracting additional numbers of not only Russian citizens, but also foreign citizens. The integrated model of key competencies is universal and can be applied to any position and field of activity.
\end{abstract}

Key words: digitalization, digital technologies, human resources, competence, model, health resort complex, medical services.

Citation. Simchenko N.A., Yanovskaya A.A. Development of the Personnel Potential of a Sanatorium-Resort Complex in the Digital Transformation of Economy. Journal of Volgograd State University. Economics, 2020, vol. 22, no. 2, pp. 148-160. (in Russian). DOI: https://doi.org/10.15688/ek.jvolsu.2020.2.14

УДК 331.101

Дата поступления статьи: 20.02.2020

ББК 65.24

Дата принятия статьи: 23.03.2020

\section{РАЗВИТИЕ КАДРОВОГО ПОТЕНЦИАЛА САНАТОРНО-КУРОРТНОГО КОМПЛЕКСА В УСЛОВИЯХ ЦИФРОВОЙ ТРАНСФОРМАЦИИ ЭКОНОМИКИ ${ }^{1}$}

Наталия Александровна Симченко

Крымский федеральный университет им. В.И. Вернадского, г. Симферополь, Российская Федерация

\section{Анна Анатольевна Яновская}

Крымский федеральный университет им. В.И. Вернадского, г. Симферополь, Российская Федерация

Аннотация. Существующие организационные и экономические отношения санаторно-курортных учреждений Республики Крым и влияние их кадрового потенциала на повышение качества предоставляемых медицинских услуг предопределяют необходимость разработки предложения по увеличению экспорта ме- 
дицинских услуг в санаторно-курортном комплексе республики посредством трансформации компетенций персонала в условиях цифровизации. При изучении зарубежных и отечественных научных работ выявлено влияние процесса цифровизации на трансформации в занятости населения, а также определена взаимосвязь трех составляющих эффективного рабочего процесса: автоматизации, занятости и производительности труда. В процессе проведения анализа официальных статистических показателей санаторно-курортной сферы определено, что доходы от предоставляемых услуг санаторно-курортных организаций имеют тенденцию роста. Вместе с тем значения показателей среднесписочной численности работников санаторно-курортных учреждений и численности размещенных иностранных граждан имеют наибольшее отрицательное отклонение. По результатам исследования разработана модель ключевых компетенций персонала, предоставляющих медицинские, лечебные, оздоровительные и реабилитационные услуги в санаторно-курортном комплексе. Модель направлена на увеличение качества санаторно-курортных услуг и привлечение дополнительного объема численности не только граждан РФ, но и иностранных граждан. Интегрированная модель ключевых компетенций является универсальной и может применяться для любой должности и сферы деятельности.

Ключевые слова: цифровизация, цифровые технологии, кадровый потенциал, компетенция, модель, санаторно-курортный комплекс, медицинские услуги.

Цитирование. Симченко Н. А., Яновская А. А. Развитие кадрового потенциала санаторно-курортного комплекса в условиях цифровой трансформации экономики // Вестник Волгоградского государственного университета. Экономика. - 2020. - Т. 22, № 2. - C. 148-160. - DOI: https://doi.org/10.15688/ek.jvolsu.2020.2.14

\section{Введение}

На современном этапе развития учреждений санаторно-курортного комплекса главной их социальной целью является поддержание и укрепление здоровья населения. Опыт предоставляемых медицинских услуг санаторно-курортными учреждениями Российской Федерации начинается еще с советских времен, поэтому нынешняя санаторная система построена на современных рыночных отношениях, основанных на внедрении «умных» технологий, а также обладающих высокой степенью коммерциализации, что позволило укрепить свою роль в развитии курортных дестинаций. Однако устойчивое функционирование санаторно-курортного комплекса и уровень качества предоставляемых медицинских услуг невозможны без высококвалифицированного и компетентного персонала. В связи с этим актуальным является исследование организации медицинских услуг в санаторно-курортном комплексе посредством трансформации компетенций персонала в условиях цифровизации.

Объектом исследования являются структурные и региональные проблемы, присущие санаторно-курортному комплексу Республики Крым, решение которых позволит улучшить эффективность деятельности таких организаций и позволит вывести крымский регион на новый стратегический уровень социально-экономического развития.
Предметом исследования выступают существующие организационные и экономические отношения санаторно-курортных учреждений Республики Крым и влияние их кадрового потенциала на повышение качества предоставляемых медицинских услуг.

Цель исследования - разработать предложения по увеличению экспорта медицинских услуг в санаторно-курортном комплексе Республики Крым посредством трансформации компетенций персонала в условиях цифровизации экономики.

Актуальность исследования основана на реализации Указа Президента Российской Федерации от 07.05.2018 № 204 «О национальных целях и стратегических задачах развития Российской Федерации на период до 2024 года», в соответствии с которым разработаны национальные проекты федерального масштаба по трем направлениям: «Человеческий капитал», «Комфортная среда для жизни» и «Экономический рост», а также Национальная стратегия развития искусственного интеллекта до 2030 г., утвержденная 10 октября 2019 года.

В связи с этим нами была выбрана сфера исследования по направлению развития «Человеческий капитал», в частности, национальный проект «Здравоохранение», одной из задач которого является увеличение объема экспорта медицинских услуг. Республика Крым вносит огромный вклад в решение национальных задач в области здравоохранения, с одной стороны, внедряются новые техноло- 
гии на базе современных многопрофильных медицинских центров, с другой стороны, имеется огромный многолетний опыт в клиническом лечении, оздоровлении и реабилитации. Ведь Крым с его природным, рекреационным наследием и инфраструктурным обеспечением по праву может считаться всероссийской здравницей.

Новизна исследования заключается в системном анализе влияния процесса цифровизации на трансформацию компетенций персонала, предоставляющих медицинские услуги, с учетом региональной отраслевой специализации: развития санаторно-курортного лечения, оздоровления и реабилитации.

Рабочая гипотеза исследования основана на предположении, что усиление трансформации компетенций персонала в условиях цифровизации экономики позволит увеличить объем экспорта медицинских услуг в санаторно-курортных учреждениях Республики Крым.

Проанализировав научные публикации зарубежных авторов, отметим, что аналогом отечественного термина «санаторно-курортные услуги» являются понятия «wellness resort» и «health resort and spa», под которыми понимается методика ведения здорового образа жизни, основанная на сочетании физического и ментального здоровья, правильного питания, разумных физических нагрузок и отказа от вредных привычек. В отличие от перечня услуг санаторно-курортного комплекса за рубежом, российская санаторно-курортная система предоставляет помимо оздоровительных, восстановительных и реабилитационных программ еще и медицинские услуги, основанные на консервативных методах лечения.

Рассмотрим результаты научных исследований, отражающих влияние процесса цифровизации на трансформации в занятости населения. Так, ряд зарубежных исследователей выдвигает предположение о тесной взаимосвязи трех составляющих рабочего процесса: автоматизации, занятости и производительности труда [McKinsey Global Institute ..., 2017]. Другие авторы отмечают, что с учетом интенсификации цифровой экономики необходимо в первую очередь модернизировать трудовое законодательство [Cherry, 2016; Harris, 2015]. Коллектив авторов [Goos et al., 2015] в своем исследовании подсчитал, что каждое высокотех- нологичное рабочее место в регионе создает пять дополнительных низкотехнологичных рабочих мест в этом регионе из-за наличия местного мультипликатора высокотехнологичных рабочих мест. Зарубежные исследователи отмечают, что в среднем только $9 \%$ рабочих мест с высокой степенью вероятности будут автоматизированы. В то же время отмечено, что на европейском рынке труда $40 \%$ работников с низким средним образованием заняты на работах с высоким риском автоматизации труда, менее $5 \%$ работников с высшим образованием заняты на работах с высоким риском автоматизации труда [Arntz et al., 2016]. Таким образом, обеспечение устойчивости, адаптивности и эффективности рынка труда является не только вопросом удовлетворения потребностей в компетентности и навыках персонала в цифровых технологиях, но и предпосылкой социальной стабильности и устойчивого развития [Kergroach, 2017, p. 6-8].

Так, по мнению М.И. Муслимова [Муслимов, 2018, с. 63-74], для достижения цели внедрения цифровых технологий в сферу здравоохранения необходимо умение кадрового ресурса адаптироваться к новой «цифровой» реальности.

В сфере здравоохранения к процессу цифровизации можно отнести: внедрение медицинских информационных систем, применение инновационных IT-продуктов на различных технологических платформах, интегрированные в единое информационное медицинское пространство (например, Единая государственная информационная система в сфере здравоохранения), интернет вещей, в частности, применение телемедицинских технологий. Например, в Нидерландах использование последних позволило сократить количество госпитализаций больных с сердечно-сосудистой патологией на $64 \%$, а само время госпитализации сократить на 87 \% [Попова, 2017, с. 11-15]. В США около 30 \% первичных обращений к врачу проходит с применением телемедицинских сервисов, в России согласно проведенным исследованиям больше половины опрошенных готовы обращаться к врачу дистанционным способом [Муслимов, 2018, с. 66-68].

Таким образом, мы рассмотрели основные тенденции изменений в области управления рынком труда и его развития в процессе 
цифровизации, представленные российскими и зарубежными исследователями. Далее рассмотрим влияние цифровизации на развитие санаторно-курортного комплекса.

Российскими учеными определены факторы, влияющие на удовлетворенность потребителей санаторно-курортными услугами, к которым относятся: цель поездки, источники оплаты за проезд, выбор места проживания, режим организации отдыха, уровень здравоохранения в курортной дестинации, а также уровень расходов туристов. На основании исследования рынка санаторно-курортных услуг выявлена взаимосвязь между удовлетворенностью клиентов, влияющими факторами и лояльностью туристов к месту отдыха, то есть туристской дестинацией [Factors Affecting Domestic ..., 2013, p. 1162-1173].

Автором [Цёхла, 2019, с. 859] выделены ключевые факторы развития санаторно-оздоровительных услуг в процессе цифровых трансформаций, к которым относятся внедрение новых технологий обслуживания и расширение ассортимента услуг, а также реализация региональной стратегии экспорта услуг санаторно-курортного комплекса.

Авторами [Karpova et al., 2018; Коржачкина, 2012, с. 63-69] определены характерные структурные проблемы в деятельности санаторно-курортного комплекса в процессе цифровизации: проблемы инфраструктуры, проблемы нормативно-правового уровня, проблемы социального уровня, проблемы экономического уровня. К проблемам регионального развития санаторно-курортного комплекса относятся сложности с равномерным обеспечением доступа к лечению по конкретным видам заболеваний, вопрос транспортной инфраструктуры, различный уровень плотности населения и процесс ускоренной урбанизации в ряде российских регионов и др.

Исследователи [Оборин и др., 2017, c. 128-144] разработали систему продвижения рынка санаторно-курортных услуг региона, используя современные методы marketing mix «5С» и «7Р», ориентированные на сферу услуг. Другие авторы [Клейман и др., 2016, с. 57-62; Лаврова, 2017, с. 190-195] для интенсивного развития и интеграции санаторно-курортного комплекса в цифровую экономику предлагают реализовывать государственные программы по развитию данной отрасли посредством форм государственно-частного партнерства.

На наш взгляд, научные рекомендации и предложения авторов [Романова, 2015, с. 9799] по развитию и созданию Центров оценки и сертификации квалификаций (далее - ЦОСК) в сфере предоставления медицинских и санаторно-курортных услуг вызывают научный интерес и являются перспективным направлением. Результаты исследования [Романова, 2015, с. 97-99] относительно ЦОСК выявили, что его структура не позволяет создавать постоянно действующие комиссии из штатных членов Центра, которые в силу своей деятельности должны мобильно формироваться по мере потребности в аттестации квалификаций персонала соответствующего направления сферы санаторно-курортного комплекса. Тем не менее отраслевые особенности обусловливают необходимость использования широкого набора практических инструментов оценки, что требует организации специализированной инфраструктуры или проведения аттестации в условиях действующих санаторно-курортных учреждений. В таком случае авторами [Романова, 2015, с. 97-99] предложено создавать ЦОСК в форме автономных структурных подразделений в рамках профильных отраслевых учреждений, что, в свою очередь, обеспечивается более низкой стоимостью услуг, улучшает информационный обмен с работодателями санаторно-курортного комплекса. Однако, исходя из предложений авторов [Романова, 2015, с. 9799], мы рекомендуем развитие и создание ЦОСК с обязательным оцениванием компетенций медицинского персонала и необходимостью привлечения иностранных экспертов в состав ЦОСК, тем самым это станет одним из направлений, увеличивающих объем экспорта медицинских услуг санаторно-курортного комплекса Республики Крым.

В соответствии с утвержденным Паспортом Национального проекта «Международная кооперация и экспорт», включающим в себя пять направлений федеральных проектов, один из которых «Экспорт услуг», разработана и утверждена «Стратегия развития экспорта услуг на период до 2025 года». Согласно данному документу разработаны меры по упрощению визового режима иностранным гражданам, включая расширение применения элек- 
тронных виз. Например, с целью поездки «Лечение» срок выдачи одно- и двукратных виз сокращен до трех дней.

Считаем целесообразным включить в перечень регионов, использующих электронные визы для иностранных граждан Республику Крым, что приведет к увеличению объема экспорта санаторно-курортных, медицинских, оздоровительных и других сопутствующих услуг. Также необходимо в рамках регионального экспортного стандарта разработать целевую карту либо локальную стратегию развития экспорта туристских и санаторно-курортных услуг в Республике Крым.

Всемирной организацией здравоохранения проведено исследование в области повышения компетентности медицинских кадров [Langins, Borgermans, 2015] и представлена последовательность различных этапов цикла закрепления компетенций (см. рисунок).

Цикл закрепления компетенций начинается с процессов, которые инициируются на уровне системы здравоохранения и заканчиваются процессами, которые инициируются организациями на этапе предоставления медицинских услуг.

Таким образом, изучив влияние цифровых технологий на трансформации в кадро- вых ресурсах организаций и влияние процесса цифровизации на развитие санаторно-курортного комплекса, необходимо разработать интегрированную модель ключевых компетенций для организаций санаторно-курортного комплекса.

\section{Методика}

Достоверность научных результатов исследования обоснована обобщением и модернизацией организационно-экономического процесса управления санаторно-курортными учреждениями Республики Крым и влияния их кадрового потенциала на повышение качества предоставляемых услуг, которые обеспечивают процесс увеличения объема экспорта медицинских услуг в санаторно-курортном комплексе и развитие экономики локального и регионального уровня. Использование экономико-статистической информации и ее авторское преобразование, согласованность авторских выводов, результатов и предложений, формирование актуальной методологической и информационной базы позволили обеспечить высокий научный уровень формулирования и достижения целей и задач данного научного исследования в час-

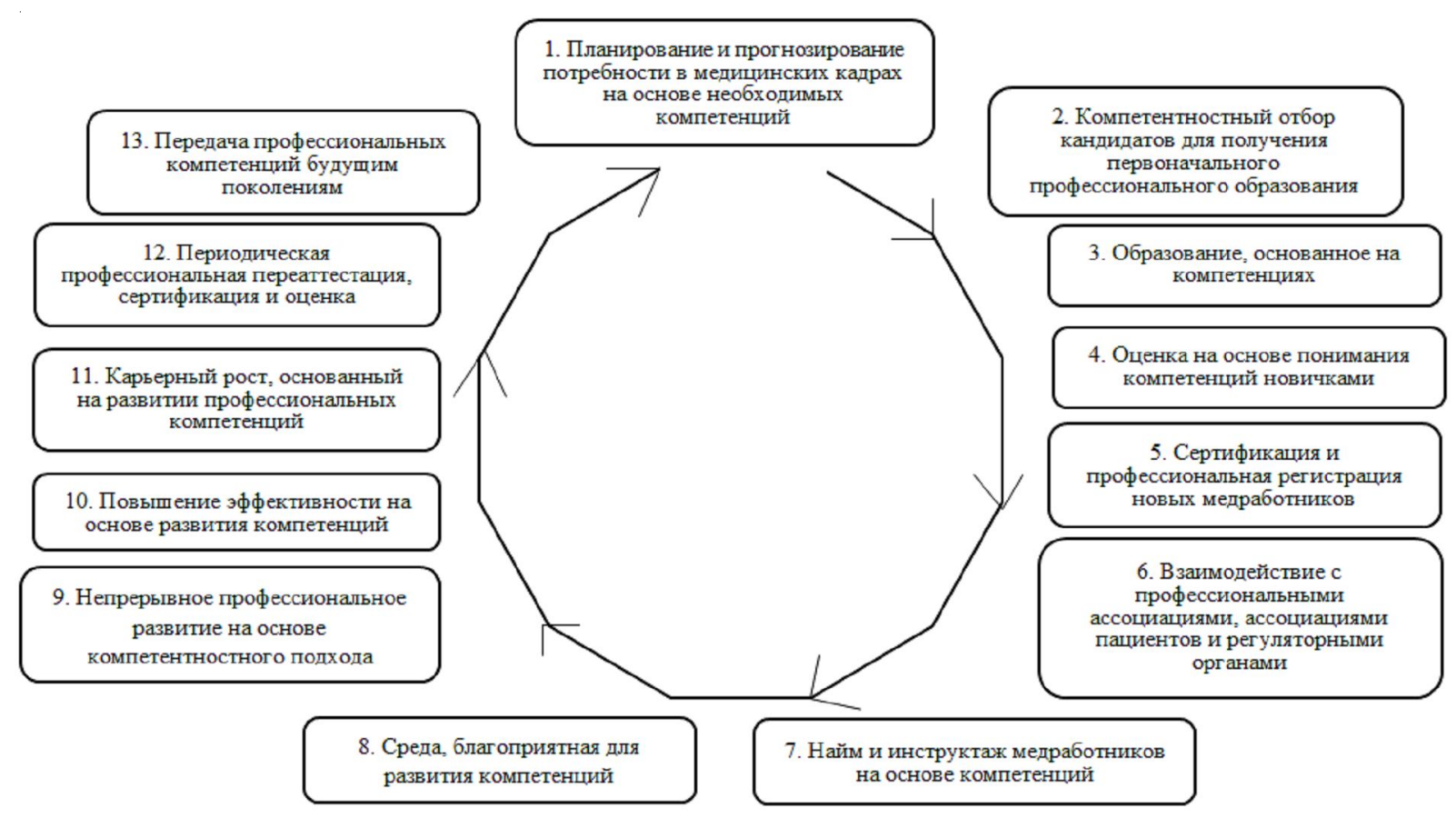

Рисунок. Цикл закрепления компетенций медицинских работников

Примечание. Составлено авторами. 
ти определений условий увеличения экспорта медицинских услуг в санаторно-курортном комплексе Республики Крым посредством трансформации компетенций персонала в условиях цифровизации.

Ценность исследования состоит в расширении научных знаний в области изучения влияния цифровизации на кадровый потенциал, его трансформации - на компетентность персонала санаторно-курортных учреждений. Кроме того, она выражена в приращении качества методического обеспечения процесса мониторинга, оценки и анализа данных санаторно-курортных учреждений по объему оказания медицинских услуг иностранным гражданам на основе комплексных интегрированных оценок.

Таким образом, авторские выводы, результаты и предложения научного исследования могут быть использованы в качестве теоретического базиса в определении влияния цифровизации на кадровый потенциал санаторно-курортных учреждений, стратегий развития экспортно ориентированных медицинских учреждений и санаторно-курортных организаций, региональных исследований увеличения объема экспорта медицинских услуг и потенциала устойчивого развития санаторно-курортного комплекса Республики Крым.

\section{Результаты и обсуждение}

Исследования подтверждают, что мероприятия, направленные на обеспечение соответствия знаний и навыков медицинского персонала потребностям населения, решают вопрос потенциальной нехватки и диспропорции в распределении медицинских работников, повышают производительность, удовлетворенность работой, облегчают поиск, отбор и прием медицинского работника, а также позволяют мотивировать персонал и в целом способствуют улучшению качества медицинских услуг.

Предлагаем понимать под общим термином «компетенции медицинского персонала в санаторно-курортном комплексе» обязательное соблюдение медицинскими работниками стандартов в процессе предоставления медицинских, лечебных, оздоровительных и реабилитационных услуг. Таким образом, компетенции персонала напрямую связаны с улучшением качества санаторно-курортных услуг и показателей здоровья потребителей таких услуг.

В таблице 1 представлены официальные статистические данные по показателям санаторно-курортной сферы 2014-2018 гг., которые разделены на три группы: общие показатели санаторно-курортного комплекса, показатели

\section{Показатели санаторно-курортной сферы}

Таблийа 1

\begin{tabular}{|c|c|c|c|c|c|}
\hline Показатель & 2014 г. & 2015 г. & 2016 г. & 2017 г. & 2018 г. \\
\hline \multicolumn{6}{|c|}{ Общие показатели санаторно-курортного комплекса } \\
\hline Объем платных санаторно-курортных услуг, млн руб. & $\mathrm{H} /$ д & 7932,7 & 7546,4 & 6818,8 & 7627,6 \\
\hline $\begin{array}{l}\text { Среднесписочная численность работников санаторно- } \\
\text { курортных учреждений, чел. }\end{array}$ & н/д & 15412 & 17998 & 13505 & 15748 \\
\hline $\begin{array}{l}\text { Численность размещенных иностранных граждан по } \\
\text { цели поездки «Лечение и оздоровление», тыс. чел. }\end{array}$ & 15,7 & 11,5 & 12,3 & 11,4 & 13,2 \\
\hline \multicolumn{6}{|c|}{ Основные показатели деятельности специализированных средств размещения } \\
\hline Специализированные средства размещения, ед. & 198 & 187 & 370 & 456 & 471 \\
\hline Численность размещенных лиц граждан РФ, тыс. чел. & 211,9 & 435,9 & 723,1 & 684,5 & 1075,8 \\
\hline $\begin{array}{l}\text { Численность размещенных иностранных лиц в специа- } \\
\text { лизированных учреждениях, тыс. чел. }\end{array}$ & 22,4 & 18,0 & 28,7 & 18,6 & 21,6 \\
\hline Доходы от предоставляемых услуг ССР, млн руб. & 3596,3 & 11163,2 & 10185,1 & 14559,8 & 17725,6 \\
\hline \multicolumn{6}{|c|}{ Основные показатели деятельности санаторно-курортных организаций } \\
\hline Число организаций, ед. & 96 & 126 & 111 & 111 & 113 \\
\hline Численность размещенных лиц граждан РФ, тыс. чел. & 176,1 & 389,4 & 402,9 & 428,1 & 718,0 \\
\hline $\begin{array}{l}\text { Численность размещенных иностранных лиц в специа- } \\
\text { лизированных учреждениях, тыс. чел. }\end{array}$ & 19,8 & 13,1 & 19,7 & 14,1 & 16,3 \\
\hline Доходы от предоставляемых услуг СКО, млн руб. & 3311,0 & 10556,4 & 9181,3 & 11278,4 & 13636,6 \\
\hline
\end{tabular}

Примечание. Составлено авторами по материалам исследования. 
специализированных средств размещения и показатели деятельности санаторно-курортных организаций.

Обращаем внимание, что при проведении статистического анализа экономических показателей санаторно-курортной сферы динамический ряд представлен в виде абсолютного прироста и темпа прироста по каждому показателю (табл. 2).

Анализ официальных статистических данных показывает, что объем платных санаторно-курортных услуг в течение 20152017 гг. сокращался, однако в 2018 г. данный показатель увеличился на 808,8 млн руб. или на 10,6 \% по сравнению с 2017 годом. Среднесписочная численность работников в санаторно-курортной сфере значительно сократилась в 2017 г. на 33,3 \%, но в 2018 г. темп прироста показателя составил 14,2 \%. Сокращение показателя «численность размещенных иностранных граждан по цели поездки «Лечение и оздоровление» в санаторно-курортных учреждениях наблюдается в 2015 г. и в 2017 г. на 4,2 тыс. чел. (на 36,5 \%) от предыдущего года и на 0,9 тыс. чел. (на 7,9 \%), соответственно.

Динамика количества специализированных средств размещения отражает поступательный рост - на 183 (почти на 50 \% в сравнении с 2015 г.) учреждения показатель увеличился в 2016 г. (это объясняется завершением переходного периода и соответствие крымских санаторно-курортных учреждений законодательным и нормативным требованиям, предъявляемым к российским учреждениям санаторно-курортной сферы), на 86 учреждений пополнился санаторно-курортный комплекс в 2017 г. и на 15 учреждений в 2018 г., то есть наблюдается регрессия показателя. По показателю «численность размещенных

Динамика показателей санаторно-курортной сферы

Таблиия 2

\begin{tabular}{|c|c|c|c|c|c|c|c|c|}
\hline Показатель & $\Delta_{2015}$ & $\Delta_{2016}$ & $\Delta_{2017}$ & $\Delta_{2018}$ & $\begin{array}{l}\text { Тпр } 2015, \\
\% \\
\end{array}$ & $\begin{array}{c}\text { Тпр } 2016, \\
\%\end{array}$ & $\begin{array}{c}\text { Тпр } 2017, \\
\%\end{array}$ & $\begin{array}{c}\text { Тпр } 2018, \\
\%\end{array}$ \\
\hline \multicolumn{9}{|c|}{ Общие показатели санаторно-курортного комплекса } \\
\hline $\begin{array}{l}\text { Объем платных санаторно- } \\
\text { курортных услуг, млн руб. }\end{array}$ & - & $-386,3$ & $-727,6$ & 808,8 & - & $-4,87$ & $-10,7$ & 10,6 \\
\hline $\begin{array}{l}\text { Среднесписочная численность } \\
\text { работников санаторно- } \\
\text { курортных учреждений, чел. }\end{array}$ & - & 2586 & -4493 & 2243 & - & 14,4 & $-33,3$ & 14,2 \\
\hline $\begin{array}{l}\text { Численность размещенных ино- } \\
\text { странных граждан по цели по- } \\
\text { ездки «Лечение и оздоровле- } \\
\text { ние», тыс. чел. }\end{array}$ & $-4,2$ & 0,8 & $-0,9$ & 1,8 & $-36,5$ & 6,5 & $-7,9$ & 13,6 \\
\hline \multicolumn{9}{|c|}{ Основные показатели деятельности специализированных средств размещения } \\
\hline $\begin{array}{l}\text { Специализированные средства } \\
\text { размещения, ед. }\end{array}$ & -11 & 183 & 86 & 15 & $-5,9$ & 49,5 & 18,9 & 3,2 \\
\hline $\begin{array}{l}\text { Численность размещенных лиц } \\
\text { граждан РФ, тыс. чел. }\end{array}$ & 224 & 287,2 & $-38,6$ & 391,3 & 51,4 & 39,7 & $-5,6$ & 36,4 \\
\hline $\begin{array}{l}\text { Численность размещенных ино- } \\
\text { странных лиц в специализиро- } \\
\text { ванных учреждениях, тыс. чел. }\end{array}$ & $-4,4$ & 10,7 & $-10,1$ & 3,0 & $-24,4$ & 37,3 & $-54,3$ & 13,9 \\
\hline $\begin{array}{l}\text { Доходы от предоставляемых } \\
\text { услуг ССР, млн руб. }\end{array}$ & 7566,9 & $-978,1$ & 4374,7 & 3165,8 & 67,8 & $-9,6$ & 30,0 & 17,9 \\
\hline \multicolumn{9}{|c|}{ Основные показатели деятельности санаторно-курортных организаций } \\
\hline Число организаций, ед. & 30 & -15 & 0 & 2 & 23,8 & $-13,5$ & 0 & 1,8 \\
\hline $\begin{array}{l}\text { Численность размещенных лиц } \\
\text { граждан РФ, тыс. чел. }\end{array}$ & 213,3 & 13,5 & 25,2 & 289,9 & 54,8 & 3,4 & 5,9 & 40,4 \\
\hline $\begin{array}{l}\text { Численность размещенных ино- } \\
\text { странных лиц в специализиро- } \\
\text { ванных учреждениях, тыс. чел. }\end{array}$ & $-6,7$ & 6,6 & $-5,6$ & 2,2 & $-51,1$ & 33,5 & $-39,7$ & 13,5 \\
\hline $\begin{array}{l}\text { Доходы от предоставляемых } \\
\text { услуг СКО, млн руб. }\end{array}$ & 7245,4 & $-1375,1$ & 2097,1 & 2358,2 & 68,6 & $-15,0$ & 18,6 & 17,3 \\
\hline
\end{tabular}

Примечание. Составлено авторами по материалам исследования. 
лиц граждан Российской Федерации» наблюдается динамика роста, в среднем годовой абсолютный прирост составил 225 тыс. человек. По показателю «численность иностранных граждан, размещенных в специализированных средствах размещения» динамика неоднозначная: в 2017 г. количество иностранных граждан сократилось на 10,1 тыс. чел., сокращение составило 54,3 \%, однако в 2018 г. данный показатель увеличился на 3 тыс. чел. в сравнении с 2017 годом. Положительная динамика роста наблюдается по показателю «доходы от предоставляемых услуг специализированных средств размещения» с 2017 года.

Поступательная динамика роста наблюдается по показателю «численность размещенных лиц граждан РФ в санаторно-курортных организациях» в течение исследуемого периода. Однако отмечается неоднозначная динамика численности иностранных граждан в санаторно-курортных учреждениях - на 50 \% показатель сократился в 2016 г. и на 40 \% - в 2017 году. Доходы от предоставляемых услуг санаторнокурортных организаций возрастают, средний ежегодный темп прироста составил $26 \%$.

По показателям санаторно-курортной сферы «среднесписочная численность работников санаторно-курортных учреждений» и «численность размещенных иностранных граждан по цели поездки “Лечение и оздоровление"» наблюдается наибольшее отрицательное отклонение.

Таким образом, исходя из результатов анализа, необходимо разработать модель ключевых компетенций персонала, предоставляющих медицинские, лечебные, оздоровительные и реабилитационные услуги в санаторнокурортном комплексе. Модель направлена на увеличение качества санаторно-курортных услуг и привлечение дополнительного объема численности не только граждан РФ, но и иностранных граждан (см. табл. 3).

Интегрированная модель ключевых компетенций для организаций санаторно-курортного комплекса представляет собой наличие четырех предметных областей, по каждой из которых определен соответствующий набор компетенций. Далее расшифрованы уровни владения компетенцией, которыми должен обладать сотрудник организации в зависимости от занимаемой должности. Требуемый уровень в бал- лах - это эталонная модель, которой должен соответствовать сотрудник, другими словами это эталонный уровень развития компетентности персонала. Исходя из данных интегрированной модели, предложен расчет показателя «уровень соответствия ключевым компетенциям». Приведем пример расчета предлагаемого показателя для должности врача санаторно-курортного учреждения, применяя разработанную интегрированную модель ключевых компетенций (см. табл. 4).

Таким образом, расчет показателя «уровень соответствия ключевым компетенциям» для должности врача санаторно-курортного учреждения составил 87,7 \%. Данная интегрированная модель ключевых компетенций является универсальной и может применяться для любой должности и сферы деятельности. Руководство организации может определять любую предметную область и формировать соответствующий им набор компетенций в зависимости от вида деятельности и структуры организации.

\section{Заключение}

При изучении зарубежных и отечественных научных работ выявлено влияние процесса цифровизации на трансформации в занятости населения, а также определена взаимосвязь трех составляющих эффективного рабочего процесса: автоматизации, занятости и производительности труда. Однако, как показал анализ литературных источников, с учетом влияния цифровизации и внедрения цифровых технологий имеется проблема несовершенства трудового законодательства и компетентности персонала в умении адаптироваться и обладать многозадачностью в условиях новой «цифровой» реальности.

Определено влияние цифровизации на развитие санаторно-курортного комплекса. Определены сегменты, в которых выявлены проблемы на инфраструктурном, нормативно-правовом, социальном и экономическом уровнях.

Исследование научных разработок некоторых отечественных авторов позволило сделать вывод о целесообразности развития и создания Центра оценки и сертификации квалификаций с обязательной процедурой оцени- 
вания компетенций медицинского персонала и необходимостью привлечения иностранных экспертов в состав ЦОСК. Тем самым это станет одним из направлений, которые позволят увеличить объем экспорта медицинских услуг санаторно-курортного комплекса Республики Крым.

Наше исследование проводилось с учетом реализации федерального проекта «Экспорт услуг», который включен в структуру Паспорта Национального проекта «Междуна- родная кооперация и экспорт». На основании анализа этого документа в рамках регионального экспортного стандарта разработать целевую карту либо локальную стратегию развития экспорта туристских и санаторно-курортных услуг в Республике Крым.

Проведен анализ показателей санаторно-курортной сферы Республики Крым, определено текущее состояние и динамика ее развития, уровень кадрового потенциала. По результатам анализа разработана модель клю-

Интегрированная модель ключевых компетенций

Таблица 3 для организаций санаторно-курортного комплекса

\begin{tabular}{|c|c|c|c|c|c|c|c|}
\hline \multirow{2}{*}{$\begin{array}{c}\text { Пред- } \\
\text { метная } \\
\text { область }\end{array}$} & \multirow{2}{*}{ Компетенция } & \multicolumn{5}{|c|}{ Уровень владения } & \multirow{2}{*}{$\begin{array}{c}\text { Требуемый } \\
\text { уровень } \\
\text { в баллах }\end{array}$} \\
\hline & & A & B & $\mathrm{C}$ & $\mathrm{D}$ & $\mathrm{E}$ & \\
\hline \multirow{3}{*}{ 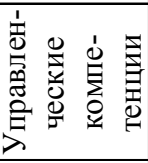 } & принятие решений & \multirow{16}{*}{ 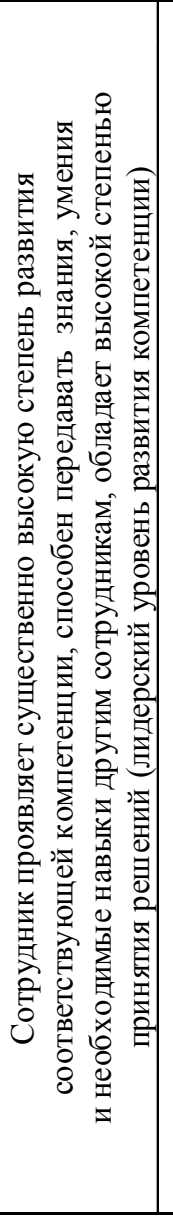 } & \multirow{16}{*}{ 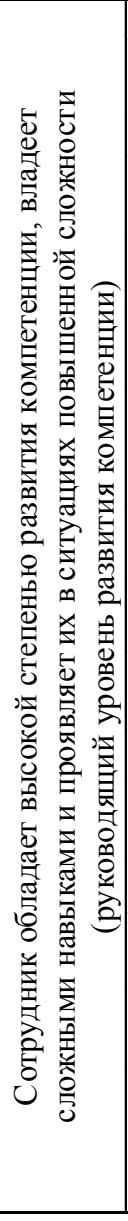 } & \multirow{16}{*}{ 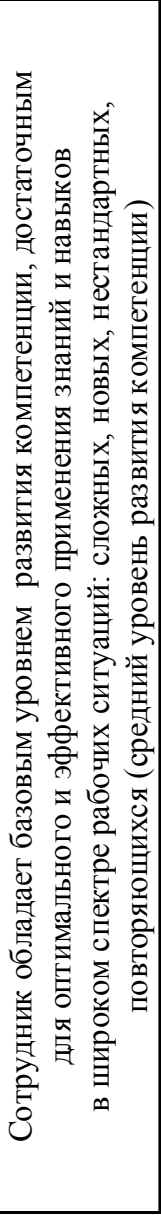 } & \multirow{16}{*}{ 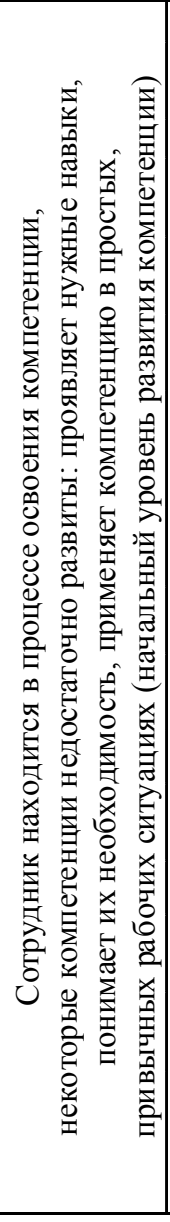 } & \multirow{16}{*}{ 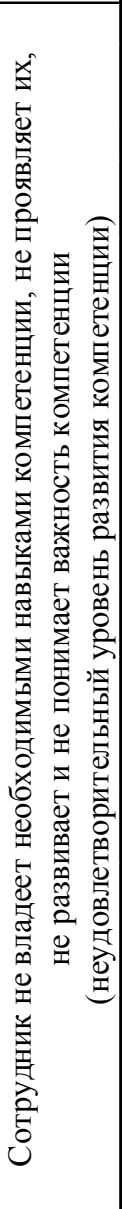 } & 4 \\
\hline & $\begin{array}{c}\text { стратегическое и аналитиче- } \\
\text { ское мышление }\end{array}$ & & & & & & 10 \\
\hline & управление конфликтами & & & & & & 8 \\
\hline \multirow{4}{*}{ 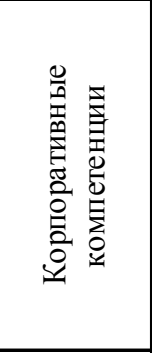 } & $\begin{array}{c}\text { ориентация на саморазвитие, } \\
\text { непрерывное обучение }\end{array}$ & & & & & & 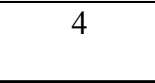 \\
\hline & $\begin{array}{l}\text { организационная } \\
\text { сознательность }\end{array}$ & & & & & & 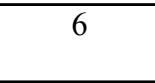 \\
\hline & $\begin{array}{c}\text { целостность и привержен- } \\
\text { ность ценностям }\end{array}$ & & & & & & 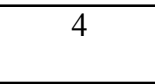 \\
\hline & $\begin{array}{c}\text { эффективная коммуникация } \\
\text { и обмен информацией } \\
\text { с персоналом }\end{array}$ & & & & & & - \\
\hline \multirow{3}{*}{ 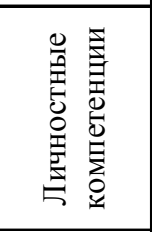 } & $\begin{array}{c}\text { общий, социальный } \\
\text { и эмоциональный интеллект }\end{array}$ & & & & & & 8 \\
\hline & инициативность & & & & & & 6 \\
\hline & $\begin{array}{r}\text { профес } \\
\text { увер }\end{array}$ & & & & & & 6 \\
\hline \multirow{6}{*}{ 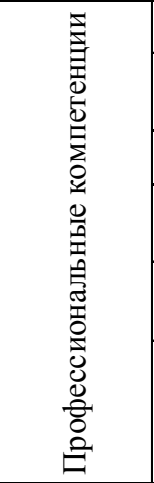 } & клиентоориентированность & & & & & & 10 \\
\hline & $\begin{array}{c}\text { адаптивность } \\
\text { и многозадачность }\end{array}$ & & & & & & 8 \\
\hline & ориентация на результат & & & & & & 10 \\
\hline & $\begin{array}{c}\text { работа в составе многопро- } \\
\text { фильной команды }\end{array}$ & & & & & & 6 \\
\hline & $\begin{array}{c}\text { уровень квалификации, зна- } \\
\text { ние своей работы }\end{array}$ & & & & & & 10 \\
\hline & $\begin{array}{c}\text { обеспечение качества струк- } \\
\text { туры и процесса предостав- } \\
\text { ления работ или услуг }\end{array}$ & & & & & & 8 \\
\hline 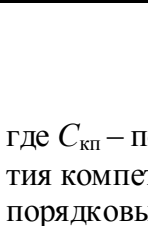 & D & Z & $\frac{\mathrm{KT}_{j}}{2 \sigma_{j}} \times$ & 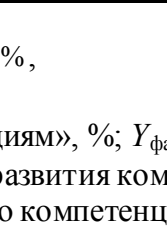 & 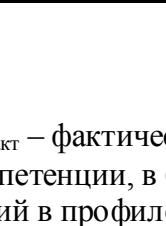 & & a3B \\
\hline
\end{tabular}

Примечание. Составлено автором по данным: [Reznikova et al., 2019, p. 49-59; Верна, 2018, c. 531]. 


\section{Пример расчета показателя «уровень соответствия ключевым компетенциям»} для должности врача санаторно-курортного учреждения

\begin{tabular}{|c|c|c|}
\hline & Компетенция & $\begin{array}{l}\text { Требуемый уро- } \\
\text { вень в баллах / } \\
\text { Фактический } \\
\text { уровень в баллах }\end{array}$ \\
\hline \multirow{3}{*}{$\begin{array}{c}\text { Управленческие } \\
\text { компетенции }\end{array}$} & принятие решений & $4 / 4$ \\
\hline & стратегическое и аналитическое мышление & $10 / 8$ \\
\hline & управление конфликтами & $8 / 8$ \\
\hline \multirow{4}{*}{$\begin{array}{c}\text { Корпоративные } \\
\text { компетенции }\end{array}$} & ориентация на саморазвитие, непрерывное обучение & $4 / 4$ \\
\hline & организационная сознательность & $6 / 4$ \\
\hline & целостность и приверженность ценностям & $4 / 4$ \\
\hline & эффективная коммуникация и обмен информацией с персоналом & $6 / 4$ \\
\hline \multirow{3}{*}{$\begin{array}{l}\text { Личностные } \\
\text { компетенции }\end{array}$} & общий, социальный и эмоциональный интеллект & $8 / 6$ \\
\hline & инициативность & $6 / 4$ \\
\hline & профессиональная уверенность & $6 / 6$ \\
\hline \multirow{6}{*}{$\begin{array}{c}\text { Профессиональные } \\
\text { компетенции }\end{array}$} & клиентоориентированность & $10 / 10$ \\
\hline & адаптивность и многозадачность & $8 / 6$ \\
\hline & ориентация на результат & $10 / 10$ \\
\hline & работа в составе многопрофильной команды & $6 / 6$ \\
\hline & уровень квалификации, знание своей работы & $10 / 10$ \\
\hline & $\begin{array}{l}\text { обеспечение качества структуры и процесса предоставления работ } \\
\text { или услуг }\end{array}$ & $8 / 6$ \\
\hline \multicolumn{3}{|c|}{$C_{K \Pi}=\frac{\sum_{j=1}^{m} \text { Ү̆акт }_{j}}{\sum_{j=1}^{m} \text { Үреб }_{j}} \times 100 \%=\frac{4+8+8+4+4+4+4+6+4+6+10+6+10+6+10+6}{4+10+8+4+6+4+6+8+6+6+10+8+10+6+10+8} \times 100 \%=\frac{100}{114} \times 100 \%=87,7 \%$} \\
\hline
\end{tabular}

Примечание. Составлено авторами по материалам исследования.

чевых компетенций персонала, предоставляющих медицинские, лечебные, оздоровительные и реабилитационные услуги в санаторнокурортном комплексе. Модель направлена на увеличение качества санаторно-курортных услуг и привлечение дополнительного объема численности не только граждан РФ, но и иностранных граждан. Данная интегрированная модель ключевых компетенций является универсальной и может применяться для любой должности и сферы деятельности.

\section{ПРИМЕЧАНИЕ}

${ }^{1}$ Финансирование на выполнение проекта «Детерминанты экспорта медицинских услуг в развитии санаторно-курортного комплекса Республики Крым» в рамках гранта Государственного Совета Республики Крым молодым ученым Республики Крым от 04.02.2020 № п66-2/20.

The project "Determinants of medical services export in the development of the health resort complex of the Republic of Crimea" was funded in the framework of the grant of the State Council of the Republic of
Crimea for young scientists of the Republic of Crimea dated February 4, 2020 no. п66-2/20.

\section{СПИСОК ЛИТЕРАТУРЫ}

Верна, В. В. Моделирование компетенций менеджера по персоналу организации / В. В. Верна // Экономика и предпринимательство. - 2017. T. 2, № 8(85). - C. 529-535.

Гварлиани, Т. Е. Тенденции развития туристско-рекреационных комплексов и их особенности на юге России. Сфера обращения: проблемы и перспективы развития / Т. Е. Гварлиани, Е. К. Воробей. - Пермь : Пермский филиал Российского экономического университета им. Г.В. Плеханова, 2016. -С. 196-213.

Клейман, А. А. Анализ реализации государственных программ по развитию санаторно-курортного комплекса (на примере Краснодарского края) / А. А. Клейман, Т. Е. Гварлиани, И. В. Кожушкина // Вестник Национальной академии туризма. - 2016. - № 4 (40). - С. 57-62.

Коржачкина, Н. Б. Современное состояние и пути дальнейшего развития санаторно-курортного лечения в Российской Федерации / Н. Б. Кор- 
жачкина // Кремлевская медицина: клинический вестник. - 2012. - № 4. - С. 63-69.

Лаврова, Т. А. Государственно-частное партнерство как основа интенсивного развития туризма в России / Т. А. Лаврова, С. А. Уваров // Журнал правовых и экономических исследований. 2017. - № 2. - С. 190-195.

Langins, М. Повышение уровня компетентности медицинских кадров в целях организации согласованного/комплексного предоставления медицинских услуг : Рабочий документ. Сентябрь 2015 г. Всемирная организация здравоохранения / M. Langins, L. Borgermans. Электрон. текстовые дан. - Режим доступа: https://www.euro.who.int/_ data/assets/pdf file/0011/357437/HWF-Competencies-rus.pdf $\%$ 3Fua\%3D1 (дата обращения: 18.01.2020). - Загл. с экрана.

Муслимов, М. И. Цифровое здравоохранение - как фактор революционных преобразований в отрасли / М. И. Муслимов // Современные проблемы здравоохранения и медицинской статистики. -2018. - № 3. - С. 63-74.

Оборин, М. С. Исследование и разработка системы продвижения рынка санаторно-курортных услуг региона / М. С. Оборин // Экономический анализ: теория и практика. - 2017. - Т. 16, вып. 1. - С. 128-144.

Попова, М. А. Телеускорение / М. А. Попова // Коммерсантъ. - 2017. - № 95 (6089). - С. 11-15.

Романова, Г. М. К вопросу развития центров оценки и сертификации квалификаций в сфере рекреации и спортивно-оздоровительного туризма / Г. М. Романова, Н. А. Савельева // Теория и практика физической культуры. - 2015. - № 11. - С. 97-99.

Цёхла, С. Ю. Развитие экспорта курортных услуг в условиях цифровизации российской экономики / С. Ю. Цёхла // Большая Евразия: Развитие, безопасность, сотрудничество. - 2019. - № 2 2. - С. 857-860.

Национальный проект «Международная кооперация и экспорт». Паспорт национального проекта утвержден решением президиума Совета при Президенте Российской Федерации по стратегическому развитию и национальным проектам 24 декабря 2018 года. - Электрон. текстовые дан. - Режим доступа: http:// government.ru/projects/selection/739 (дата обращения: 15.01.2020). - Загл. с экрана.

Arntz, M. The Risk of Automation for Jobs in OECD countries: A Comparative Analysis / M. Arntz, T. Gregory, U. Zierahn // OECD Social, Employment and Migration Working Papers. 2016. - № 189. - 34 p. - DOI: http://dx.doi.org/ 10.1787/5jlz9h56dvq7-en.
Cherry, M. A. Beyond Misclassification: The Digital Transformation of Work (February 18, 2016) / M. A. Cherry // Comparative Labor Law \& Policy Journal, Forthcoming. - № 20162. - Electronic text data. - Mode of access: https:// ssrn.com/abstract $=2734288$ (date of access: 12.01.2020).

Harris, S. D. A Proposal for Modernizing Labor Laws for Twenty-First Century Work: The Independent Worker / S. D. Harris, A. B. Krueger // Discussion Paper. - 2015. - Electronic text data. - Mode of access: https://docplayer.net/19509637-Aproposal-for-modernizing-labor-laws-for-twentyfirst-century-work-the-independent-worker.html (date of access: 12.01.2020).

Goos, M. Employment Growth in Europe: The Roles of Innovation, Local Job Multipliers and Institutions / M. Goos, J. Konings, M. Vandeweyer // Utrecht School of Economics Discussion Paper Series. - 2015. - Vol. 15, № 10.

Factors Affecting Domestic Tourist's Destination Satisfaction: The Case of Russia Resorts / A. Vetitnev [et al.] // World Applied Sciences Journal. - 2013. - Vol. 22, № 8. - P. 1162-1173.

Karpova, G. A. Development Problems of Resort Complex in Transformation of the Russian Economy / G. A. Karpova, Yu. V. Dolmatenia, V. A. Tkachev// Servis v Rossii i za rubezhom.2018. - Vol. 12 (1). - P. 52-63. - DOI: https:// doi.org/10.24411/1995-042X-2018-10105.

Kergroach, S. Industry 4.0: New Challenges and Opportunities for the Labour Market / S. Kergroach // Foresight and STI Governance. 2017. - Vol. 11, No. 4. - P. 6-8. - DOI: https:// doi.org/10.17323/2500-2597.2017.4.6.8.

McKinsey Global Institute (2017). A Future that Works: Automation, Employment, and Productivity. Elecronic text data. - Mode of access: https:// www.mckinsey.com/ /media/61FCFD233FB146 38846C824CA2141C01.ashx (date of accessed: 12.01.2020).

The Importance of Human Capital in Service Sector Development Management / O. S. Reznikova [et al.] // Social Science and Humanity. - 2019. No. 2. - P. 49-59.

\section{REFERENCES}

Verna V.V. Modelirovanie kompetentsiy menedzhera po personalu organizatsii [Modeling the Managers Competencies for the Organizations Personnel]. Ekonomika i predprinimatelstvo [Economy and Entrepreneurship], 2017, vol. 2, no. $8(85)$, pp. 529-535.

Gvarliani T.E., Vorobey E.K. Tendentsii razvitiya turistsko-rekreatsionnykh kompleksov $i$ ikh 
osobennosti na yuge Rossii. Sfera obrashcheniya: problemy i perspektivy razvitiya [Trends in the Development of Tourist and Recreational Complexes and Their Features in the South of Russia. Scope of Application: Problems and Prospects for Development]. Perm, Permskiy filial Rossiyskogo ekonomicheskogo universiteta im. G.V.Plekhanova, 2016, pp. 196-213.

Kleyman A.A., Gvarliani T.E., Kozhushkina I.V. Analiz realizatsii gosudarstvennykh programm po razvitiyu sanatorno-kurortnogo kompleksa (na primere Krasnodarskogo kraya) [Analysis of the Implementation of State Programs for the Development of the Health Resort Complex (On the Example of the Krasnodar Region)]. Vestnik Natsionalnoy akademii turizma [Bulletin of the National Academy of Tourism], 2016, no. 4 (40), pp. 57-62.

Korzhachkina N.B. Sovremennoe sostoyanie i puti dalneyshego razvitiya sanatorno-kurortnogo lecheniya v Rossiyskoy Federatsii [Current State and Ways of Further Development of Health Resort Treatment in the Russian Federation]. Kremlevskaya meditsina: klinicheskiy vestnik [The Kremlin Medicine-Clinical Bulletin], 2012, no. 4, pp. 63-69.

Lavrova T.A., Uvarov S.A. Gosudarstvenno-chastnoe partnerstvo kak osnova intensivnogo razvitiya turizma v Rossii [Public-Private Partnership as a Basis for Intensive Tourism Development in Russia]. Zhurnal pravovykh i ekonomicheskikh issledovaniy [Journal of Legal and Economic Research], 2017, no. 2, pp. 190-195.

Langins M., Borgermans L. Povyshenie urovnya kompetentnosti meditsinskikh kadrov v tselyakh organizatsii soglasovannogo/kompleksnogo predostavleniya meditsinskikh uslug: Rabochiy dokument. Sentyabr 2015 g. Vsemirnaya organizatsiya zdravookhraneniya [Increasing the Level of Competence of Medical Personnel in Order to Organize Coordinated / Integrated Medical Services. World Health Organisation]. URL: https://www.euro.who.int/ data/assets/ pdf_file/0011/357437/HWF-Competenciesrus.pdf\% 3Fua\%3D1 (accessed 18 January 2020).

Muslimov M.I. Tsifrovoe zdravookhranenie - kak faktor revolyutsionnykh preobrazovaniy $\mathrm{v}$ otrasli [Digital Healthcare as a Factor of Revolutionary Changes in the Industry]. Sovremennye problemy zdravookhraneniya $i$ meditsinskoy statistiki [Modern Problems of Health Care and Medical Statistics], 2018, no. 3, pp. 63-74.

Oborin M.S. Issledovanie i razrabotka sistemy prodvizheniya rynka sanatorno-kurortnykh uslug regiona [Research and Development of a
System for Promoting the Market of Health Resort Services in the Region]. Ekonomicheskiy analiz: teoriya i praktika [Economic Analysis: Theory and Practice], 2017, vol. 16, no. 1,pp. 128-144.

Popova M.A. Teleuskorenie [Tele-Acceleration]. Kommersant, 2017, no. 95 (6089), pp. 11-15.

Romanova G.M., Savelyeva N.A. K voprosu razvitiya tsentrov otsenki i sertifikatsii kvalifikatsiy v sfere rekreatsii i sportivno-ozdorovitelnogo turizma [On the Issue of Developing Centers for Assessment and Certification of Qualifications in the Field of Recreation and Sports Tourism]. Teoriya i praktika fizicheskoy kultury [Theory and Practice of Physical Culture], 2015, no. 11, pp. 97-99.

Tsekhla S.Yu. Razvitie eksporta kurortnykh uslug v usloviyakh tsifrovizatsii rossiyskoy ekonomiki [Development of Export of Resort Services in the Conditions of Digitalization of the Russian Economy]. Bolshaya Evraziya: Razvitie, bezopasnost, sotrudnichestvo [Greater Eurasia: Development, Security, and Cooperation], 2019, no. 2-2, pp. 857-860.

Natsionalnyy proekt "Mezhdunarodnaya kooperatsiya i eksport». Pasport natsionalnogo proekta utverzhden resheniem prezidiuma Soveta pri Prezidente Rossiyskoy Federatsii po strategicheskomu razvitiyu i natsionalnym proektam 24 dekabrya 2018 goda [National Project "International Cooperation and Export". The National Project Passport Was Approved by the Decision of the Presidium of the Presidential Council for Strategic Development and National Projects on December 24, 2018]. URL: http:// government.ru/projects/selection/739/ (accessed 15 January 2020).

Arntz M., Gregory T., Zierahn U. The Risk of Automation for Jobs in OECD Countries: A Comparative Analysis. OECD Social, Employment and Migration Working Papers, 2016, no. 189. 34 p. DOI: http://dx.doi.org/ 10.1787/5jlz9h56dvq7-en.

Cherry M.A. Beyond Misclassification: The Digital Transformation of Work (February 18, 2016). Comparative Labor Law \& Policy Journal, Forthcoming, no. 2016-2. URL: https://ssrn.com/ abstract $=2734288$ (accessed 12 January 2020).

Harris S.D., Krueger A.B. A Proposal for Modernizing Labor Laws for Twenty-First Century Work: The Independent Worker. Discussion Paper, 2015. URL: https://docplayer.net/19509637-Aproposal-for-modernizing-labor-laws-fortwenty-first-century-work-the-independentworker.html (accessed 12 January 2020).

Goos M., Konings J., Vandeweyer M. Employment Growth in Europe: The Roles of Innovation, 


\section{УПРАВЛЕНИЕ ЭКОНОМИЧЕСКИМ РАЗВИТИЕМ}

Local Job Multipliers and Institutions. Utrecht School of Economics Discussion Paper Series, 2015, vol. 15, no. 10.

Vetitnev A., Romanova G., Matushenko N., Kvetenadze E. Factors Affecting Domestic Tourists Destination Satisfaction: The Case of Russia Resorts. World Applied Sciences Journal, 2013, vol. 22, no. 8, pp. 1162-1173.

Karpova G.A., Dolmatenia Yu.V., Tkachev V.A. Development Problems of Resort Complex in Transformation of the Russian Economy. Servis $v$ Rossii i za rubezhom, 2018, vol. 12 (1), pp. 5263. DOI: $10.24411 / 1995-042 X-2018-10105$.
Kergroach S. Industry 4.0: New Challenges and Opportunities for the Labour Market. Foresight and STI Governance, 2017, vol. 11, no. 4, pp. 68. DOI: 10.17323/2500-2597.2017.4.6.8.

McKinsey Global Institute. "A Future that Works: Automation, Employment, and Productivity”. 2017. URL: https://www.mckinsey.com/ /media/ 61FCFD233FB14638846C824CA2141C01.ashx (accessed 12 January 2020).

Reznikova O.S., Kruglov D.V., Ganieva A.K., Verna V.V. The Importance of Human Capital in Service Sector Development Management. Social Science and Humanity, 2019, no. 2, pp. 49-59.

\section{Information About the Authors}

Natalia A. Simchenko, Doctor of Sciences (Economics), Professor, Head of Department of Economic Theory, V.I. Vernadsky Crimean Federal University, Sevastopolskaya St., 21/4, 295015 Simferopol, Russian Federation, natalysimchenko@yandex.ru, https://orcid.org/0000-0001-8364-2313

Anna A. Yanovskaya, PhD, Associate Professor, Department of Personnel Management, V.I. Vernadsky Crimean Federal University, Sevastopolskaya St., 21/4, 295015 Simferopol, Russian Federation, anna_net88@mail.ru, https://orcid.org/0000-0003-0247-5643

\section{Информация об авторах}

Наталия Александровна Симченко, доктор экономических наук, профессор, заведующая кафедрой экономической теории, Крымский федеральный университет им. В.И. Вернадского, ул. Севастопольская, 21/4, 295015 г. Симферополь, Российская Федерация, natalysimchenko@yandex.ru, https://orcid.org/0000-0001-8364-2313

Анна Анатольевна Яновская, $\mathrm{PhD}$, доцент кафедры управления персоналом, Крымский федеральный университет им. В.И. Вернадского, ул. Севастопольская, 21/4, 295015 г. Симферополь, Российская Федерация, anna_net88@mail.ru, https://orcid.org/0000-0003-0247-5643 